\title{
Numerical Modelling of Fish Passage with Turning Pools
}

\author{
Lukasz Maniecki \\ Wroclaw University of Science and Technology, Faculty of Civil Engineering; \\ e-mail: Lukasz.Maniecki@pwr.edu.pl \\ (Received March 07, 2018; revised June 05, 2018)
}

\begin{abstract}
An assessment of operating conditions in a baffled fish passage with pool dimensions of $2.2 \times 3.0 \mathrm{~m}$, and $180^{\circ}$ horizontally turning pools, was carried out using numerical computations and a site survey of water flow velocity distribution. Velocity was measured with a PMS electromagnetic flowmeter and a hydrometric current meter in representative cross-sections of the fish passage in the pool centres and in the baffle barrier cross-section area. Numerical computations were also performed for two alternative baffle locations in the fishway. One reflected the actual conditions, and the other was an alternative arrangement designed to improve hydraulic conditions for fish migration. The numerical model used the Large Eddy Simulation (LES) method, which makes it possible to detect large vortexes. The study pays close attention to the velocity field analysis as well as the distribution and sizes of vortexes in the turning pool of the culvert. The results of numerical computations and the site survey show high consistency, and the proposed baffle placement modification significantly improves flow conditions, especially in the entry section of the passage.
\end{abstract}

Key words: open channel flow, fishway, turbulence, numerical model, turning pool

\section{Introduction}

Fishways are a part of the river infrastructure that allows fish to migrate in both directions of the river. Nowadays, creating such ecological corridors is required in the process of designing and building new water structures. There are many types of fish passages, which are divided mainly into technical and natural fishways. A more detailed classification can be found in Clay (1995), Katopodis and Williams (2012) and FAO/DVWK (2002). Currently the most common technical fishways are the pool type, the vertical slot type with one or more slots between pools, and the Denil fish pass, all presented in Figure 1. There are also other types of technical fish passes, such as rock fishladders (Wyrębek 2013), cell-based fishways (Mortula 2011), baffled culverts (Khodier and Tullis 2013) or portable fishways (Yasuda et al 2004).

To ensure that the new fishway works correctly, the distribution of stream lines, water velocity fields, turbulence characteristics, resting zones and attraction streams should be defined at the design phase. Many researchers have investigated how the 
a)
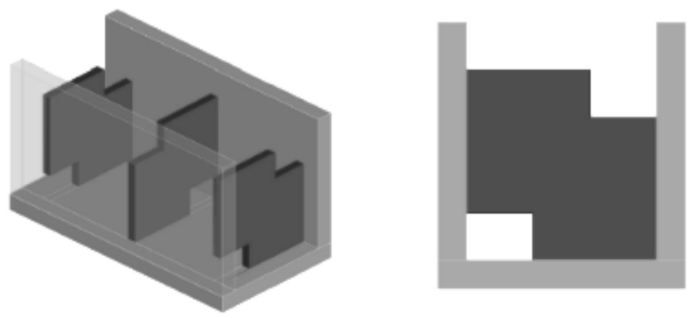

b)
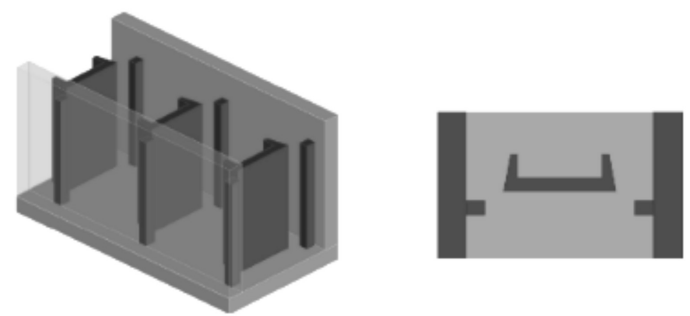

c)

d)
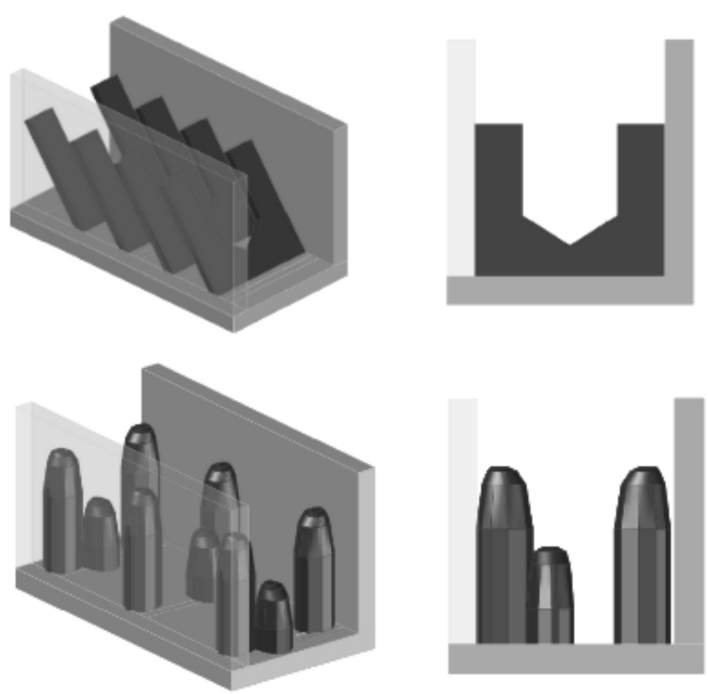

Fig. 1. The most popular technical fishways: a) pool type; b) vertical slot type (2-slot version); c) Denills type; d) Psie Pole fishway

turbulent flow characteristics affect the ability of different fish species to traverse a fish pass. Their experiments concerned such parameters as turbulence intensity (TI) (Pavlov et al 2000, Odeh et al 2002, Nikora et al 2003, Guiny et al 2005, Richmond et al 2007, Kirk et al 2016), turbulence kinetic energy (TKE) (Nikora et al 2003, Silva et al 2012, Goettel et al 2015, Delavan et al 2017), Reynolds stress (Odeh et al 2002, Silva et al 2012, Goettel et al 2015, Delavan et al 2017) and vortex size (Odeh et al 2002, Lupandin 2005, Liao 2007, Tritico and Cotel 2010, Silva et al 2012, Delavan et al 2017). General conclusions from these experiments indicate that excessive shear stress resulting from the dissipation of the stream's turbulent kinetic energy and the 
occurrence of vortices of size comparable to or greater than fish length can cause serious difficulties for fish passing through the fishway or even prevent their passage altogether.

Technical fishways consist of the series of identical pools which are easy to design and build. Sometimes, however, it is necessary to design a pool of a different shape, e.g. an arched one, because of the need to change flow direction. This can cause a water velocity increase or a flow structure that is a crucial obstacle to fish migration (Marriner et al 2014). In such a case, making proper analytical calculations is impossible, so the designers often limit their calculations to determining the mean velocity in the pool and the maximum velocity in the slots. This approach can cause errors in the design of the fishway. Due to the relevance of the problem, more and more numerical calculations have been made in recent years to optimise the pool and slot shapes and to select the best location for the fishway outlet (Lindberg et al 2013, Baek and Kim 2014).

A starting point for Computational Fluid Dynamics (CFD) modelling are the continuity equation and the equation of motion, on which the Navier-Stokes equation is based. Depending on the complexity of the problem in terms of geometry and flow conditions, one can adopt a different mathematical model, that is, the simplified Navier-Stokes equation. In simple cases, 2D depth-averaged shallow water models are often sufficient (Cea et al 2007, Alvarez-Vazquez et al 2008, Baek and Kim, 2014, Bombač et al 2014). More complex problems demand the application of 3D RANS (Reynolds-Averaged Navier-Stokes) equations, which have the advantage of yielding a solution in three dimensions, making it possible to observe flow parameters at various depths of the flow field (Barton et al 2009, Feurich et al 2012, Mao et al 2012, Lindberg et al 2013, Marriner et al 2014).

Numerical simulations of turbulent flow require the application of a proper model of turbulence. There are a great number of models in which turbulence viscosity, as a parameter of the fluid, is derived from different equations. In most cases, the $\mathrm{k}-\varepsilon$ model is used (Cea et al 2007, Barton et al 2009, Feurich et al 2012, Mao et al 2012, Lindberg et al 2013, Marriner et al 2014, Bombač et al 2014), but one can find other models, e.g. the mixing length model (Cea et al 2007), the Smagorinsky model (Bombač et al 2014) or the algebraic stress model (ASM) (Cea et al 2007).

Today, the most accurate, but also the most computation-intensive, turbulence modelling method used in practical engineering is the Large Eddy Simulation (LES). Due to the long computation time, this model is used rarely, mainly for small simulations (Lee et al 2008, Herrera-Granados 2018).

This paper presents the possibility of using a 3D numerical model for calculating water flow in a fishway with turning pools. The Large Eddy Simulation is used as a turbulence model for investigating the adverse phenomenon of water flow in turning pools. The results of calculations are compared with measurements obtained in situ, in a newly built fishway by the Psie Pole weir on the Odra river, which is a part of the Wrocław Water System. 


\section{Description of the Fish Passage}

The fish passage at the Psie Pole weir is a baffle-type fishway located at the right-side abutment of the weir on the Stara Odra river in Wrocław. The fish passage consists of twenty pools divided with baffle barriers in various arrangements. Its total length is $L=58.80 \mathrm{~m}$, and the height difference between the culvert entrance and exit is $H=1.25 \mathrm{~m}$. The length of the passage pools is $l=3.30 \mathrm{~m}$, and their width is $b=2.20$ $\mathrm{m}$. The width of the entry pool is equal to that of the passage pools, while the exit pool width narrows from $2.20 \mathrm{~m}$ to $1.10 \mathrm{~m}$. This narrowing is located at a sharp turn which also causes a change in flow direction just before the exit to the lower section of the pool. The entry and exit pools are closed by means of manually operated steel gates. The top view of the fishway is shown in Figure 2a. This passage is a hybrid of a technical fishway and a nature-like fishway with prefabricated concrete cones as baffle barriers. The untypical baffle barriers and the presence of turning pools, which alters the flow direction, entail the need for numerical calculations to properly evaluate fish migration conditions.

\section{Test Methods and Measuring Instruments}

After a site survey, several representative pools were chosen for which measuring cross sections were selected: two in the baffle axis and three in different pool areas. The location of the sections and the number of vertical lines were selected in such a way as to permit the assessment of transit streams and reverse currents, as well as the velocity field distribution. Each measurement was taken twice to avoid large incidental errors.

Measurements were made by a programmable electromagnetic liquid velocity meter (P-EMS) with a E-30 probe (Delft Hydraulics, Delft, The Netherlands) capable of measuring velocity distribution in $x$ and $y$ directions with an accuracy of $0.01 \mathrm{~ms}^{-1}$, or $1 \%$ of the measured value, at a sampling rate of $10 \mathrm{~Hz}$. Due to the limited length of the probe lance, measurements at depths of more than $1.0 \mathrm{~m}$ were made using a hydrometric current meter with a propeller diameter of $65 \mathrm{~mm}$ with an accuracy of 0.01 $\mathrm{ms}^{-1}$. Velocity measurements at each point lasted at least $120 \mathrm{~s}$ for both instruments to limit accidental errors. Preliminary measurements with both instruments indicated a full consistency of the readings in the entire range of water velocities measured. The measurements included water depth measurements in verticals, with water levels at the upper and lower positions of each pool recorded to determine the head.

Velocity field distribution diagrams were generated by the MatLab software, which was also used for flow intensity calculations. The diagram of velocity isolines was drawn using the author's own scripts with several built-in libraries, such as the cubic interpolation method or the contour plot. The flow rate was calculated by integrating the velocity field over the flow area in each section. 
b)

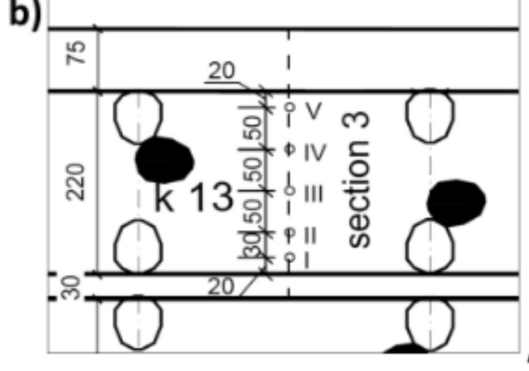

c)

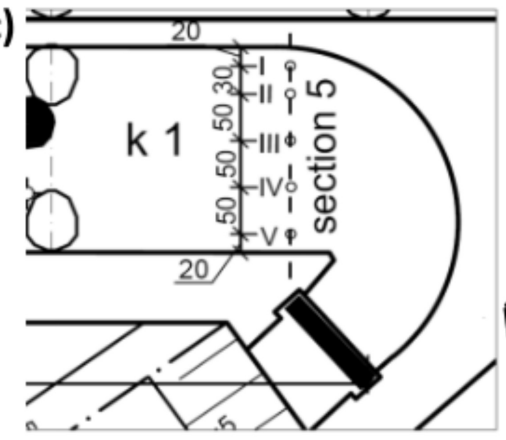

d)
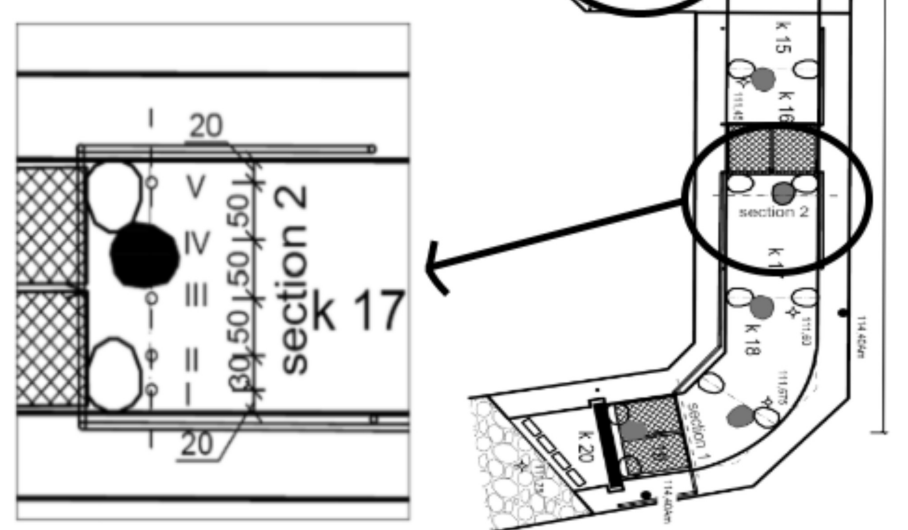

Fig. 2. Location of sections and vertical measurement lines in the Psie Pole fish passage; a) culvert top view, b) section 3, c) section 5, d) section 2

\section{Results of Velocity Measurements in the Fish Passage with Baffles}

Tests in the Psie Pole fish passage with baffles covered five measurement sections, three of which, named section 2, section 3 and section 5 , have been selected for presentation in this study. The author regards these sections as the most representative of the fishway under analysis, and they exemplify problems that may occur in such structures. Section 2 is located on the baffle axis, between pools 16 and 17 (Fig. 2d). Section 3 is located in the middle part of the pool length, behind a recirculation zone created by the baffle (Fig. 2b). Section 5 is located directly before a sharp turn, in 
which the flow width changes from $2.20 \mathrm{~m}$ to $1.10 \mathrm{~m}$ (Fig. 2c). For each section, velocity measurements were made in the direction perpendicular to the section, in five vertical measurement lines. The measurements in each line were spaced at least $0.20 \mathrm{~m}$ apart, starting from a depth of $0.10 \mathrm{~m}$ above the pool bottom. The locations of the measurement lines are shown in Figures $2 \mathrm{~b}-2 \mathrm{~d}$, and the measurement points are shown in Figures 3-5.

The distribution of water velocities in the direction perpendicular to section 2 are shown in Fig. 3. In vertical line I, at the left wall of the pool, the velocities across the entire height of the pool are uniform. They are below $0.5 \mathrm{~ms}^{-1}$, because of the presence of the baffle element just behind the measurement section. Vertical lines II and III are located just before the full slot of the baffle barrier, so the velocities there reach the highest levels of up to $1.8 \mathrm{~ms}^{-1}$ at the half-height of the section. In the lower part of the pool, the velocity decreases to about $0.7 \mathrm{~ms}^{-1}$, influenced by the proximity of the bottom. At the water surface the velocities range from $0.8 \mathrm{~ms}^{-1}$ at line II to 1.4 $\mathrm{ms}^{-1}$ at line III. Vertical line IV is located above the submerged element of the baffle barrier. Water velocities decrease gradually from $1.4 \mathrm{~ms}^{-1}$ to $0.8 \mathrm{~ms}^{-1}$ as the distance to the tall baffle element on the right side of the section decreases. In vertical line $\mathrm{V}$, a strong influence of the baffle located just behind the section is visible. Velocities across the entire height are about $0.2 \mathrm{~ms}^{-1}$, with negative values occurring at the water surface. The flow rate calculated for the section between pools 16 and 17 is $Q=2.241$ $\mathrm{m}^{3} \mathrm{~s}^{-1}$.
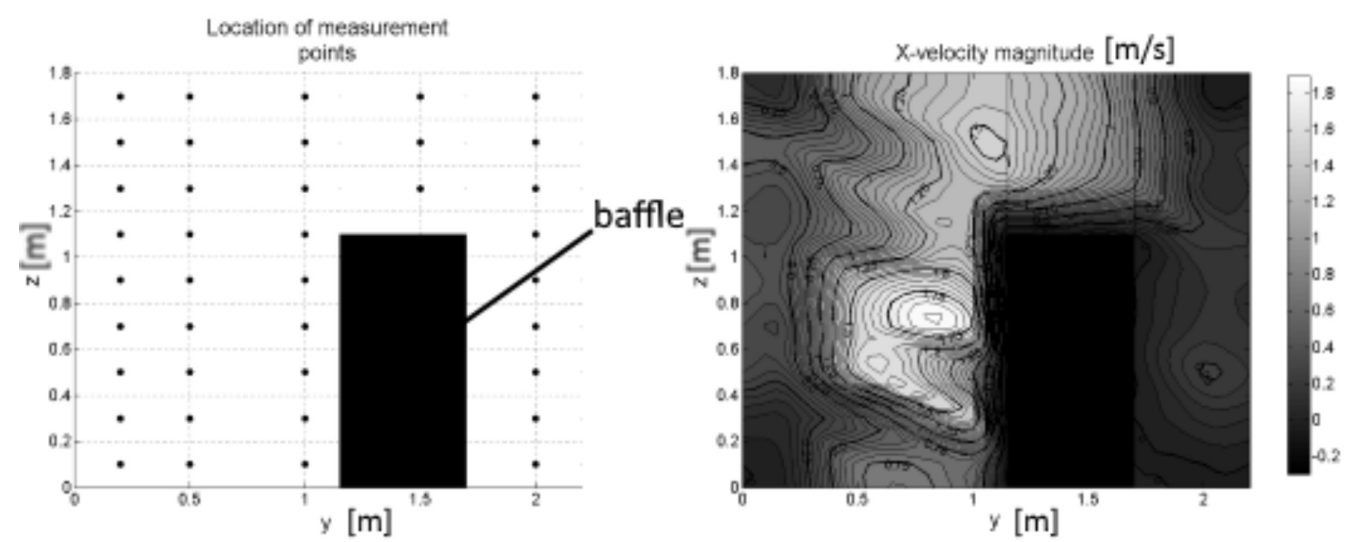

Fig. 3. Locations of measurement points and a $2 \mathrm{D}$ diagram of velocity distribution in section 2

The water velocity distribution in section 3 is shown in Fig. 4. At vertical lines I and II at the left wall of the pools, the velocities are nearly zero across the entire height, because they are measured at the border of a vertical axis vortex formed behind the baffle. Vertical line III is located in the main stream flowing out of the baffle slot, so the velocities are high. The highest value of $1.60 \mathrm{~ms}^{-1}$ occurs about the middle of 
the stream height, and the average value along the entire vertical line is $1.20 \mathrm{~ms}^{-1}$. The effect of this high velocity is shown at the right wall of the pool, at its bottom, where a strong reverse stream of about $0.5 \mathrm{~ms}^{-1}$ is visible. The flow rate calculated for section 3 is $Q=2.270 \mathrm{~m}^{3} \mathrm{~s}^{-1}$.
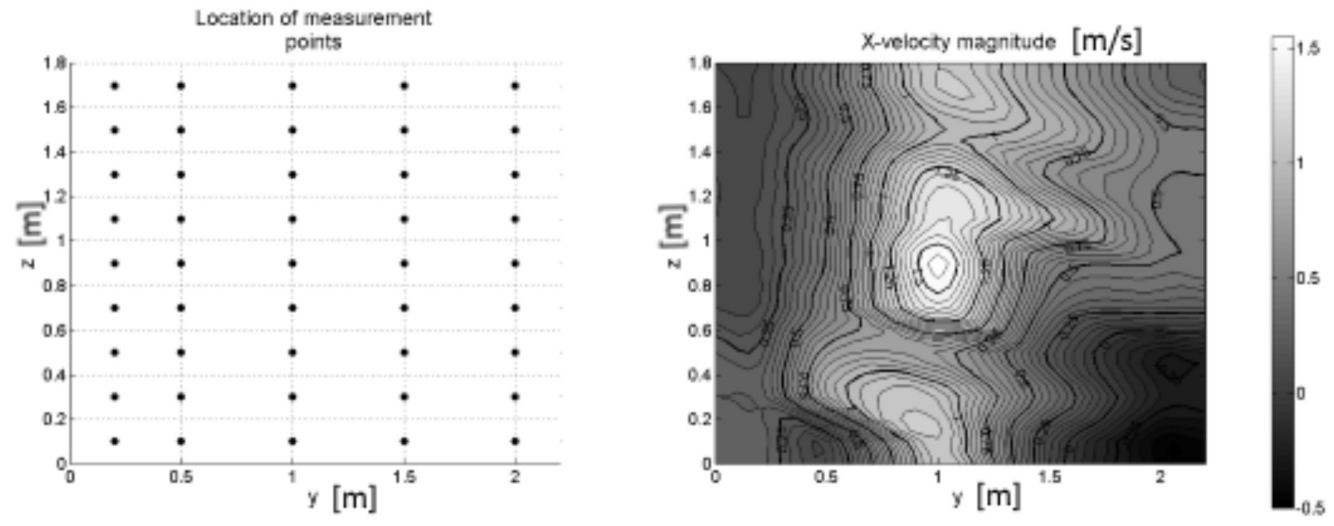

Fig. 4. Locations of measurement points and a 2D diagram of velocity distribution in section 3

Section 5 was chosen for tests because of a horizontal cylindrical water vortex that occurs there, close to the water surface along the concave arc of the fishway wall (Fig. 6). The distribution of velocities in section 5 is shown in a diagram (Fig. 5). Across the entire height of vertical lines I and II, the velocity is ca. $0.3 \mathrm{~ms}^{-1}$, except the bottom zone, where a slight reverse current occurs. Towards the right wall and the pool centre, the velocity in the successive vertical lines increases up to $1.25 \mathrm{~ms}^{-1}$ and the velocity distribution is disturbed by an array of different streams forming the velocity field under the influence of the arc and the exit narrowing from $2.20 \mathrm{~m}$ to $1.10 \mathrm{~m}$. The calculated flow rate for section 5 is $Q=2.396 \mathrm{~m}^{3} \mathrm{~s}^{-1}$.

The differences in the flow rate in the measurement sections analysed in this fishway are $6.5 \%$, and they may result from the method selected for measuring the flow rate, since the insufficiently dense grid of the measurement points may have caused errors.

\section{The Numerical Model of the Fish Passage}

Numerical computations were carried out using the Flow 3D software. This software uses the finite volume method to solve a system of differential equations describing the flow in the fishway. The computations were performed using the Large Eddy Simulation (LES) model (Gatski et al 1998).

The three-dimensional water flow is described by a Navier-Stokes equation in the following form:

$$
\frac{\partial u_{i}}{\partial t}+\frac{\partial\left(u_{i} u_{j}\right)}{\partial x_{j}}=-\frac{1}{\rho} \frac{\partial p}{\partial x_{i}}+v \frac{\partial^{2} u_{i}}{\partial x_{i} \partial x_{j}}
$$



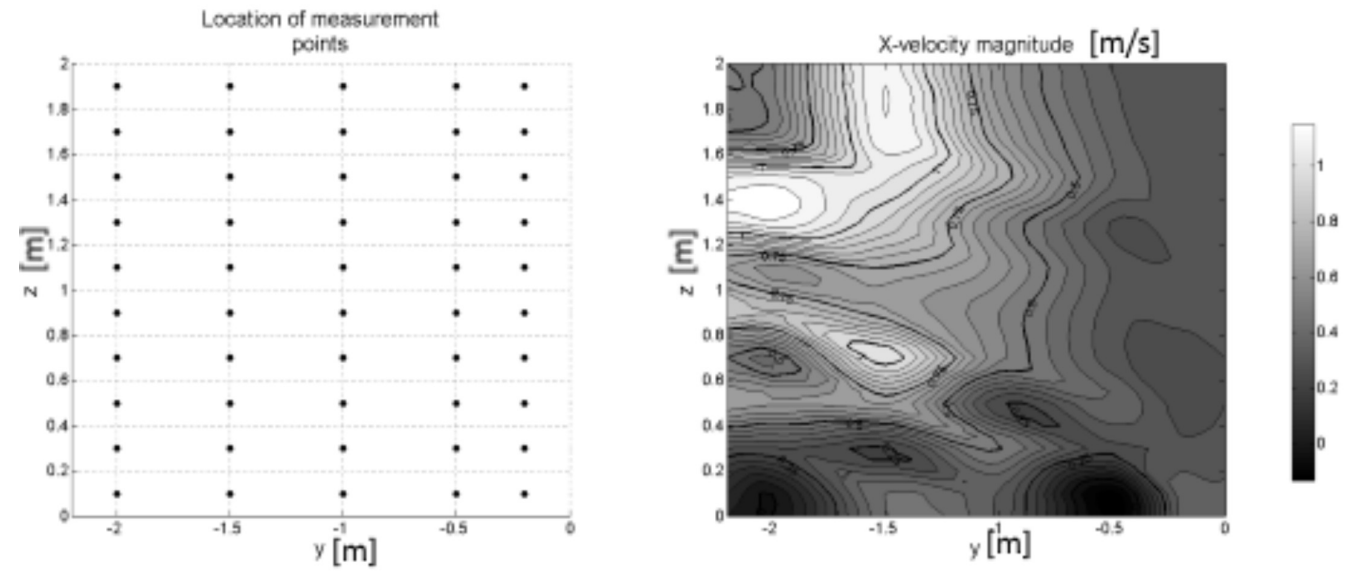

Fig. 5. Locations of measurement points and a $2 \mathrm{D}$ diagram of velocity distribution in section 5

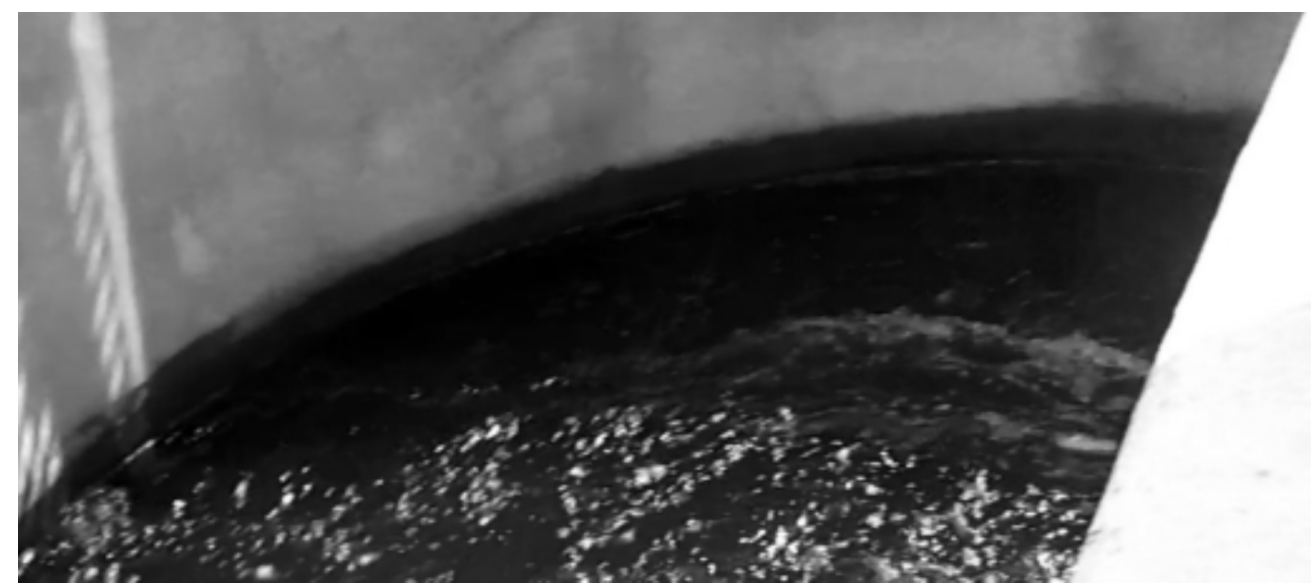

Fig. 6. Photograph of the horizontal cylindrical water vortex effect

where $u_{i}$ is one of velocity vector components, $p$ is pressure, $\rho$ is density, and $v$ is the kinematic viscosity of the fluid.

It is almost impossible to solve this equation for turbulent flow. The most common way to model the turbulent flow is to use the Reynolds-averaged Navier-Stokes (RANS) equation in which velocity is averaged using the following decomposition:

$$
u_{i}=\overline{u_{i}}+u_{i}^{\prime}
$$

where $\overline{u_{i}}$ is mean velocity, and $u_{i}^{\prime}$ represents fluctuations of velocity.

Finally, we obtain the Reynolds equations:

$$
\frac{\partial \overline{u_{i}}}{\partial t}+\frac{\partial\left(\overline{u_{i}} \overline{u_{j}}\right)}{\partial x_{j}}=-\frac{1}{\rho} \frac{\partial p}{\partial x_{i}}+v \frac{\partial^{2} \overline{u_{i}}}{\partial x_{i} \partial x_{j}}-\frac{\partial \tau_{i j}}{\partial x_{j}}
$$


where $\tau_{i j}=\overline{u_{i}^{\prime} u_{j}^{\prime}}$ are the Reynolds stresses, which must be modelled by one of turbulence models. This approach leads to some inaccuracy because of the averaging over every scale of turbulence. Therefore, in this work the Large Eddy Simulation was used. The main goal of the Large Eddy Simulation (LES) is to simulate larger eddies directly from the Navier-Stokes equation and to approximate the smaller ones in a way similar to the RANS method. An advantage of this method is that large turbulence structures contain most of the energy (70-80\%), while the smaller ones contain only $20-30 \%$ of the energy. A direct simulation of a small structure requires a very fine mesh with the size of the grid no larger than the length of the smallest eddies in all directions. This leads to a very complex mesh, which requires a lot of time and computational power, but the result is very accurate. In the LES method, such a fine mesh is not necessary, so problems can be solved faster and more accurately than by the RANS method. One can separate those two scales of turbulence by filtering the flow field as follows:

$$
\overline{u_{i}}=\int G\left(x, x^{\prime}\right) u_{i}\left(x^{\prime}\right) d x^{\prime}
$$

where $G\left(x, x^{\prime}\right)$ is the filter kernel.

After filtering the Navier-Stokes equation, we obtain an equation very similar to the RANS equation:

$$
\frac{\partial \overline{u_{i}}}{\partial t}+\frac{\partial\left(\overline{u_{i} u_{j}}\right)}{\partial x_{j}}=-\frac{1}{\rho} \frac{\partial p}{\partial x_{i}}+v \frac{\partial^{2} \overline{u_{i}}}{\partial x_{i} \partial x_{j}}
$$

and the subgrid scale (SGS) Reynolds stress:

$$
\tau_{i j}=\overline{u_{i} u_{j}}-\overline{u_{i}} \overline{u_{j}} .
$$

Then the SGS Reynold stress $\tau_{i j}$ is derived using the Smagorinsky model of turbulence. This model is based on the concept of turbulence viscosity:

$$
\tau_{i j}-\frac{1}{3} \tau_{k k} \delta_{i j}=-v_{T}\left(\frac{\partial \overline{u_{i}}}{\partial x_{j}}+\frac{\partial \overline{u_{j}}}{\partial x_{i}}\right)=-2 v_{T} \bar{D}_{i j}
$$

where $v_{T}$ is turbulence viscosity:

$$
v_{T}=(c L)^{2} \sqrt{2 e_{i j} 2 e_{i j}}
$$

where $c$ is a constant equal to $0.2, L$ is a geometric mean of grid cell dimensions, and $e_{i j}$ denotes strain rate tensor components.

The free surface flow was calculated by the Volume of Fluid (VOF) method, in which every cell of the domain contains information on the fluid volume. Water was assumed to be incompressible.

For the computational needs of the Flow 3D software, the area of interest was digitized using 8 grids (Fig. 7). There were a total of 1.1 million cubical cells with 

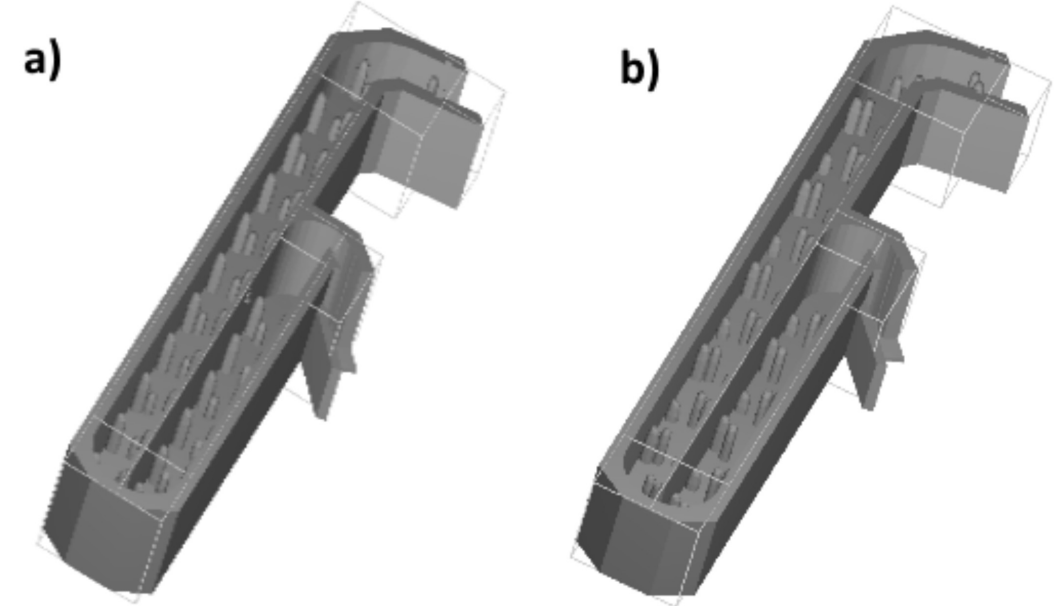

Fig. 7. 3D view of numerical models: a) Alternative I, b) Alternative II
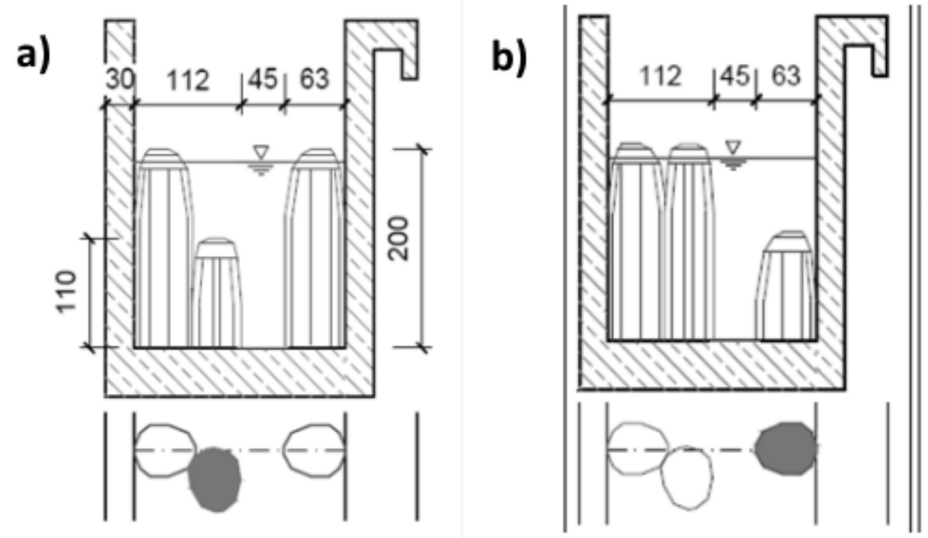

Fig. 8. Location of baffle elements in a) Alternative I, b) Alternative II

a side length of $0.1 \mathrm{~m}$. The walls, baffle elements and bottom of the fishway were modelled as a solid component with a roughness height of $0.015 \mathrm{~m}$, which corresponds to the concrete roughness. On the walls and the bottom there are the wall boundary conditions, where the normal and tangential velocities are equal to 0 . At the fishway entry (on the higher water side) the boundary condition assumed for the water table height was $H=3.75 \mathrm{~m}$, and the flow rate $Q=2.25 \mathrm{~m}^{3} \mathrm{~s}^{-1}$. At the fishway exit (on the lower water side), the water table height condition was assumed as $H=2.5 \mathrm{~m}$.

Two alternative numerical models were developed, with different baffle arrangements. Alternative I corresponds to conditions in the existing fish passage (Fig. 7a, $8 \mathrm{a}$ ), where the site survey was carried out and where two tall baffle elements are located at the walls, and another, shorter baffle element is located alternately at one or 
the other tall element. The other arrangement (Alternative II) was proposed to ameliorate flow conditions, especially the turbulences and velocity distribution patterns, and thus to improve the fishway performance. In Alternative II, two tall elements are placed alternately at one wall, and one short element at the other (Fig. 7b, 8b).

\section{Results of Numerical Computations for Alternative I}

Numerical computations for Alternative I were carried out for a period of 400 seconds, after which the flow stabilised.

The velocity computation results for section 2 , consistent with the velocity field measurements, are shown in Fig. 9. Negative values of the velocity $v_{x}$ in this section are due to the flow opposite to the direction Ox in the global system of coordinates. The distribution diagram for the velocity $v_{x}$ (Fig. 9) clearly shows a concentration of flow in the slot of the baffle barrier. Velocities in the wall zone are no higher than $0.3 \mathrm{~ms}^{-1}$, locally changing to negative values. Maximum velocities of up to $1.8 \mathrm{~ms}^{-1}$ occur just beside the submerged baffle element. The water table is visibly lower in the middle part of the pool, which is caused by water swelling before the tall baffle elements located at the walls immediately after section 2 .

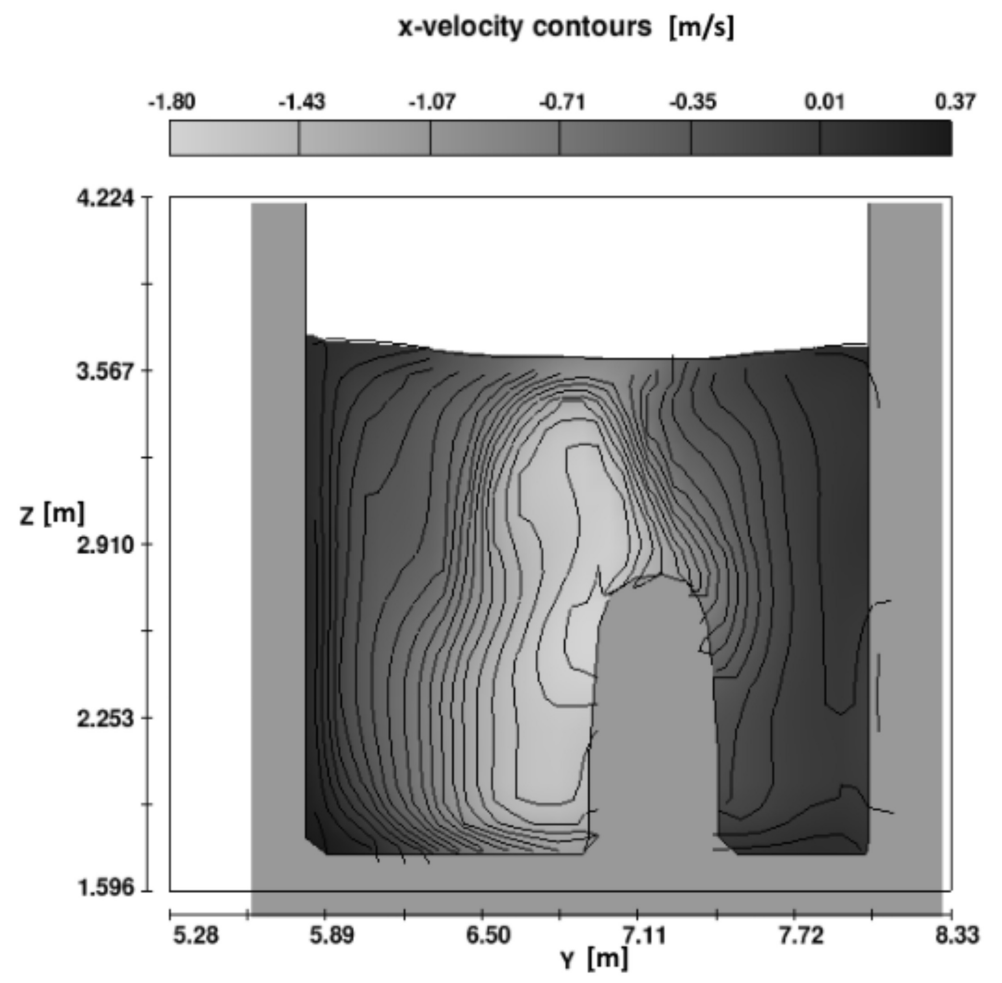

Fig. 9. Computed velocity distribution in section 2 of Alternative I 
The distribution of velocities in section 3 is shown in Figure 10. Section 3 is characterised by flow concentration around the vertical axis in the centre of the pool. This is the main stream in the pool that runs from the slot in the baffle barrier above the section to the baffle barrier below. Flow velocities there reach $1.7 \mathrm{~ms}^{-1}$. Velocities at the left wall of the pool and at the bottom are from 0.5 to $1 \mathrm{~ms}^{-1}$, whereas velocities in the mid height range from -0.1 to $0.2 \mathrm{~ms}^{-1}$, and towards the surface the velocity increases to $0.5 \mathrm{~ms}^{-1}$. At the right wall, a distinct reverse stream is visible, with velocities reaching $-0.5 \mathrm{~ms}^{-1}$.

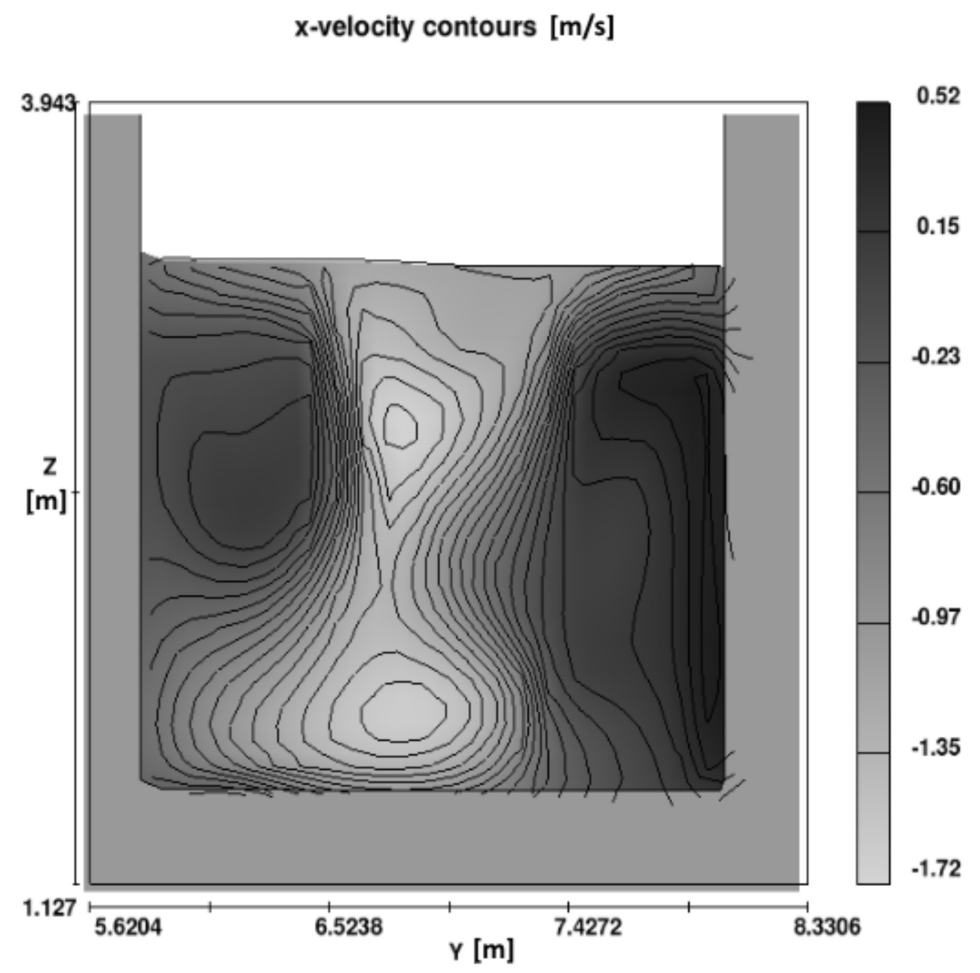

Fig. 10. Computed velocity distribution in section 3 of Alternative I

In section 5 located before the fishway exit, the main current is directed through a slot in the baffle barrier located before the section towards the left wall. The distribution of velocities in section 5 is shown in Figure 11. In this section, the flow direction is consistent with the direction $\mathrm{Ox}$ in the global coordinate system, so velocity values are positive. At the pool bottom, a reverse stream occurs across the entire width of the pool, where velocities reach $0.8 \mathrm{~ms}^{-1}$. At the left wall, velocities range from 0.8 to $1.4 \mathrm{~ms}^{-1}$, and at the right wall from 0 to $0.5 \mathrm{~ms}^{-1}$. Differences in velocities at the surface are minor. Maximum velocities of $1.45 \mathrm{~ms}^{-1}$ occur at the left wall. In the pool centre, velocity distribution is uniform, within 1 to $1.2 \mathrm{~ms}^{-1}$, and directly at the right wall the velocities drop locally to $0 \mathrm{~ms}^{-1}$, with a reverse surface stream of $0.5 \mathrm{~ms}^{-1}$. 


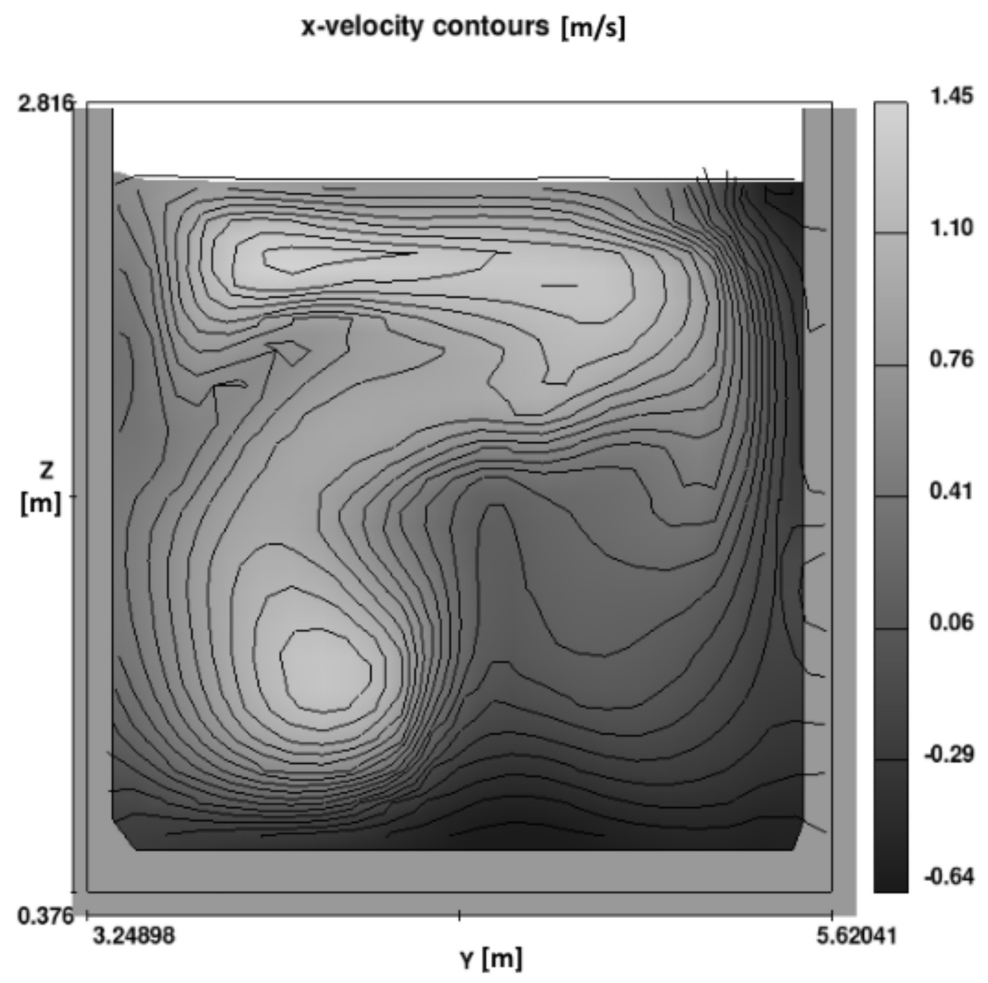

Fig. 11. Computed velocity distribution in section 5 of Alternative I

The velocity vectors in the fishway exit were also tested to obtain a more accurate description of the horizontal vortex that occurs at the exit pool arc, as observed during the site survey measurements (Fig. 6). This phenomenon seems to be quite a challenging obstacle for fish entering the fishway, especially because the size of the vortex is comparable to the size of fish.

Figure 12 shows the computed velocity vectors in 3 views at different depths in the exit pool area. View 1 shows the distribution of velocity vectors just above the bottom, at an elevation of $0.65 \mathrm{~m}$. View 2 shows the distribution of velocity vectors in the middle depth zone, at an elevation of $1.45 \mathrm{~m}$. View 3 shows the distribution of velocity vectors at the surface, at an elevation of $2.45 \mathrm{~m}$. The locations of the views are shown in Figure 13.

In Figure 12a, which shows velocity distribution at the bottom, the main stream of flow in the baffle slot is visible, directed towards the wall at the convex arc of the exit. In the larger part of the exit pool to the left of the slot, the flow velocities are very small, and a direction perpendicular to the main stream is dominant. Velocities in the arc area increase because of the narrowing cross-section of the pool and reach maximum values of up to $1.8 \mathrm{~ms}^{-1}$ at the end of the arc, at the pool end. Flow directions in the exit area are mainly parallel to the arc. 

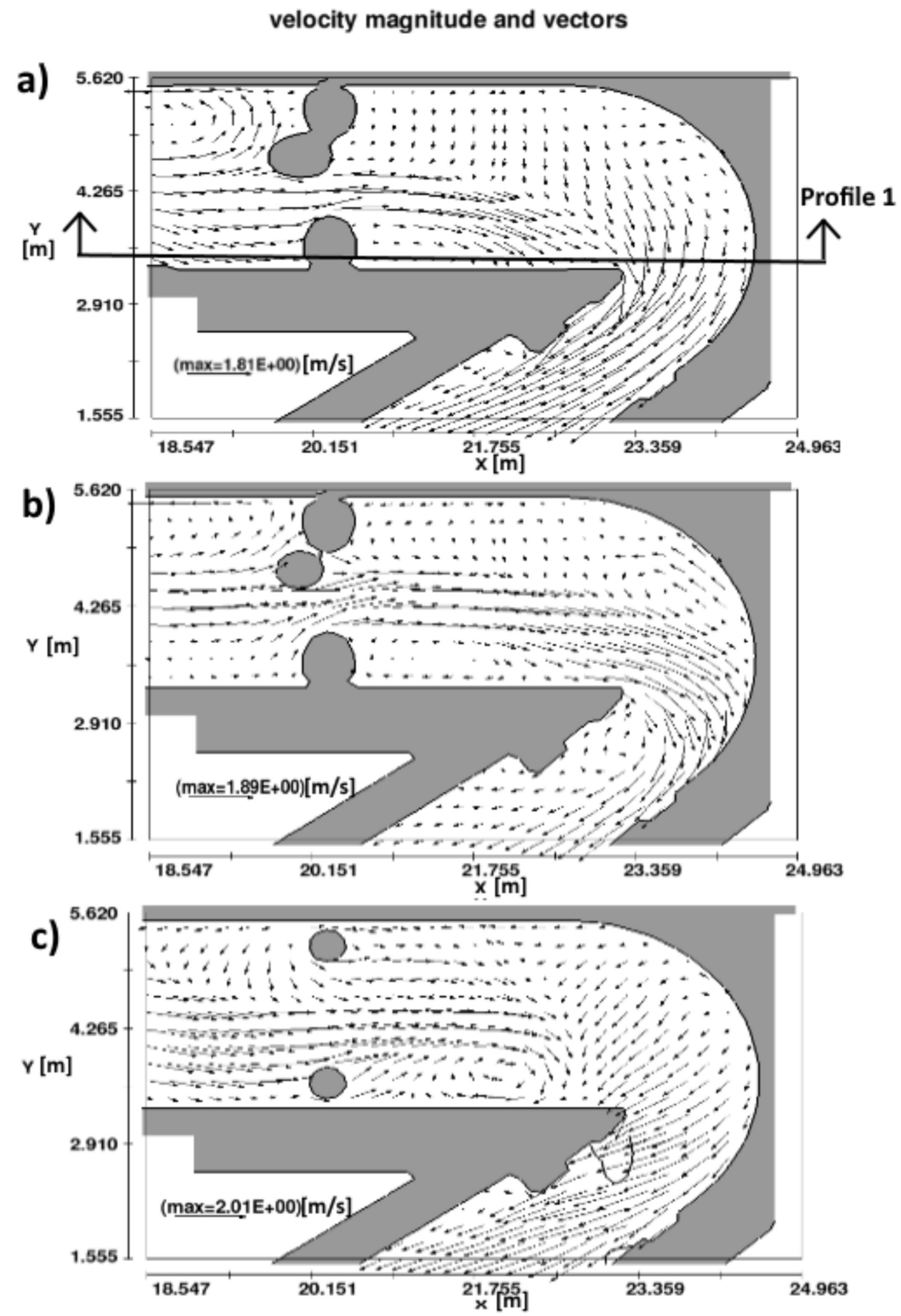

Fig. 12. Computed velocity vector distribution in the entry pool for Alternative I: a) view 1 for $z=0.65, \mathrm{~b}$ ) view 2 for $z=1.45, \mathrm{c}$ ) view 3 for $z=2.45$

Figure $12 \mathrm{~b}$ presents velocity vector distribution at the middle depth, where the main stream is not dispersed by the wall, as it is at the bottom, but is directed towards the concave side of the arc. Striking the arc wall causes part of the current to flow towards the exit, while the other part returns at the arc towards the baffle barrier, creating a vertical whirl just above the main stream. Due to the water current striking 
the arc wall at a velocity of $1.9 \mathrm{~ms}^{-1}$, only part of the ending cross-section is used effectively, because the other part is occupied by the vertical whirl.

Figure $12 \mathrm{c}$ shows velocity vector distribution at the water surface, where the main flow stream is less visible. Velocities in the baffle barrier section are uniform across the entire slot width. A large vertical whirl can be observed at the wall, before the convex arc. Velocity vectors in the concave arc zone are perpendicular to the wall, with the direction of the vector opposite to the main current. Therefore, this is the upper surface of the horizontal whirl observed during the site survey, which is created by the main current striking the wall of the concave arc. This effect is also visible in the pool exit cross-section, where velocity vectors are deflected from the exit axis by about $30^{\circ}$. This is also where velocities reach the maximum value of $2 \mathrm{~ms}^{-1}$.

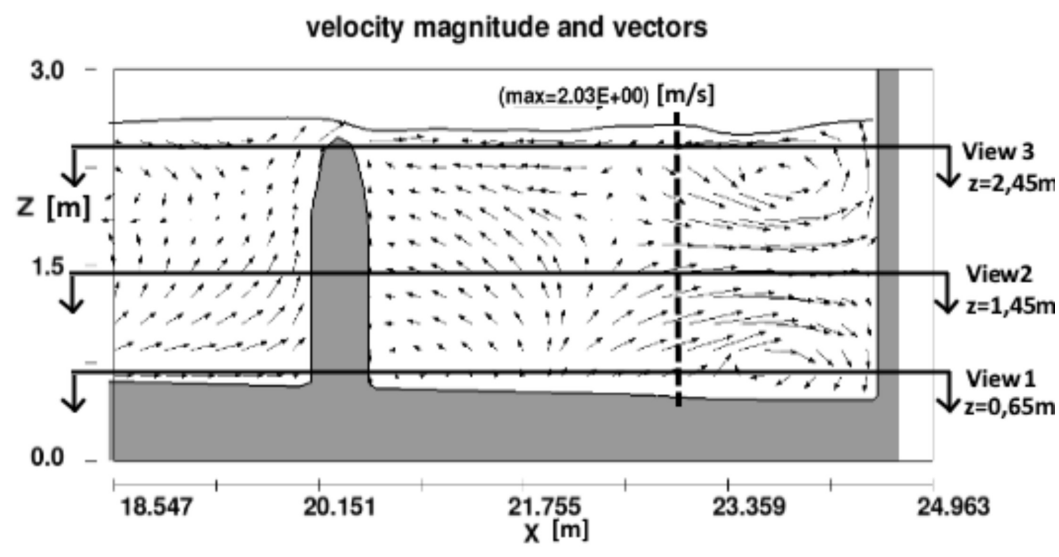

Fig. 13. Computed velocity vector distribution in profile 1 of the entry pool for Alternative I

Figure 13 shows velocity vectors in section 1, located in the exit pool, as shown in Figure 11a. At the concave arc wall, there are two clearly visible horizontal whirls, between which the water current strikes the concave arc wall. One whirl occurs at the bottom, and the other at the water surface. Their diameters are similar, about $1 \mathrm{~m}$, and the water whirls at a speed of about $0.7 \mathrm{~ms}^{-1}$. The conclusion from the diagram is that a fish that swims into the fishway must pass through the zone between the arc wall and the dashed line, indicating the approximate length of the wall at the convex arc. Therefore, the fish encounters two horizontal whirls rotating in opposite directions, or a strong water current from the left side that hits the wall. It is also worth noting the directions of vectors in the views showing the whirl formation area. They have a component parallel to the exit axis, which means that water particles move in a helix trajectory, creating additional difficulty for fish trying to swim through the exit section of the fishway. According to Odeh et al (2002), chaotic flow conditions with large vortices comparable to fish size, may jolt and spin fish, causing disorientation and potential injuries. 


\section{Comparison of Measurement Results with Computations for Alternative I}

The results of numerical computations for Alternative I show high consistency with the measurement results. In section 2, the velocity distributions for both cases (Fig. 3 and 9) are characterised by flow concentration in the slot immediately after the section and by reverse streams at the pool walls. The maximum velocities computed are identical with the values measured and occur at exactly the same locations in the section. Figure 14 compares the measured and computed velocities in a vertical situated in the middle of the full vertical slot.

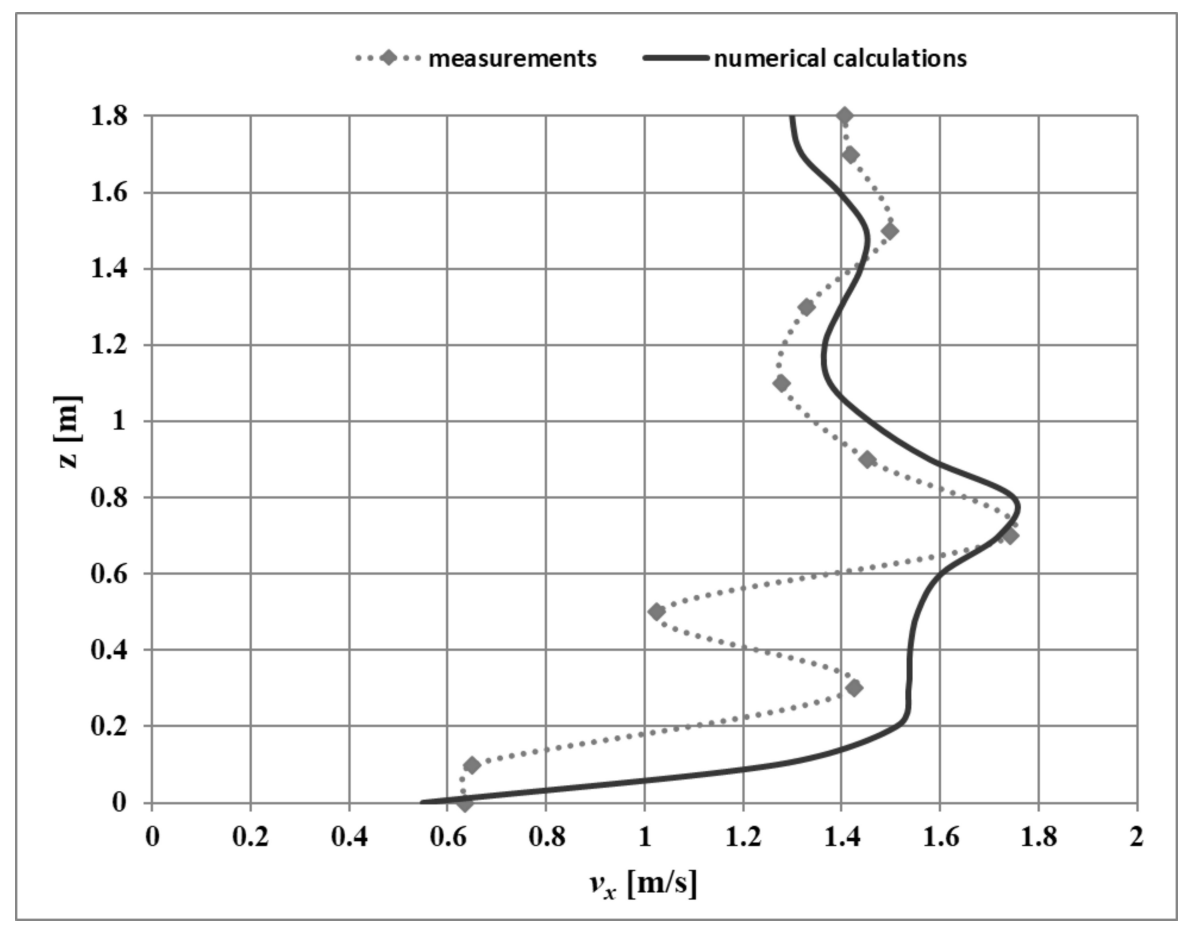

Fig. 14. Velocity distribution in section 2 in the middle of the full vertical slot

Velocity distributions in section 3 at the centre of the pool, shown in Fig. 4 and Fig. 10 , indicate the presence of the main flow stream in the vertical axis of the pool centre, where two dominant currents can be discerned. One current occurs at the bottom, and in both cases it is closer to the left wall. The other current occurs at the pool centre, and that is where the highest flow velocities are observed. The maximum measured velocities are slightly lower than the computed values. Velocities measured at the left wall and at the bottom in the right part of the section are consistent with the computed values. Locally, at the right wall in the upper part of the section, the numerical com- 
putations do not reflect the measured flow conditions. The measured and computed velocities in a vertical in the centre of pool 13 are compared in Figure 15.

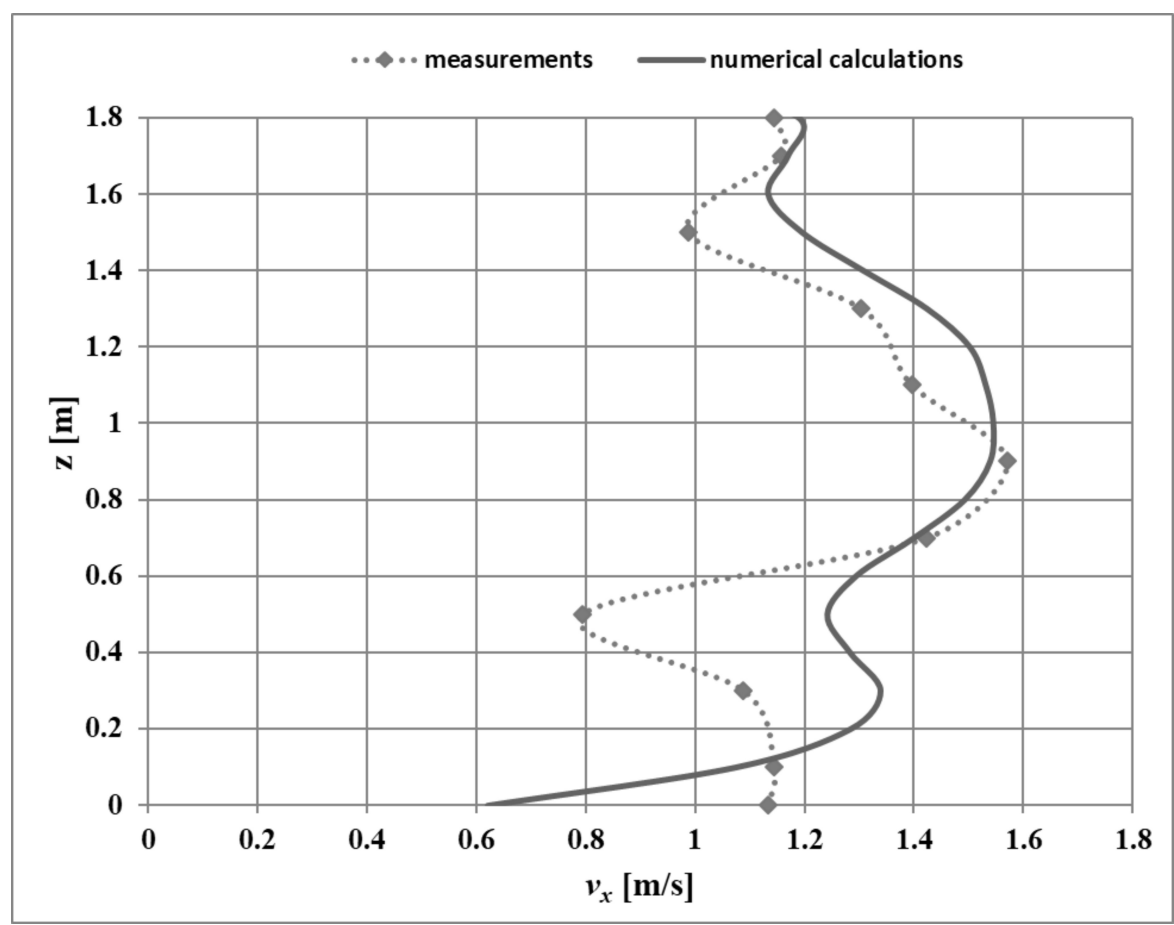

Fig. 15. Velocity distribution in section 3 in the centre of pool 13

In section 5, both measured and computed velocity distributions (Fig. 5 and 11) are characterised by flow concentration at the left wall, where two currents can be discerned, in the middle part and at the surface. The maximum velocities measured are lower than those computed. In both cases, there is a reverse stream at the bottom, but it is stronger in the computations than in the measurements. In the upper part of the section, at the right wall, the computed velocities are higher than the measured ones, while in the lower part the velocity distributions are comparable. The measured and computed velocities in a vertical situated in the centre of section 5 are compared in Figure 16.

The comparison of velocity distributions leads to the conclusion that the computations using the numerical model are a good reflection of the actual flow conditions in the fishway. The differences may be due to the insufficiently dense grid of measuring points in the sections. Despite these minor differences, it was concluded that the numerical model can be used to optimise the arrangement of baffle barriers to improve fish migration conditions. 


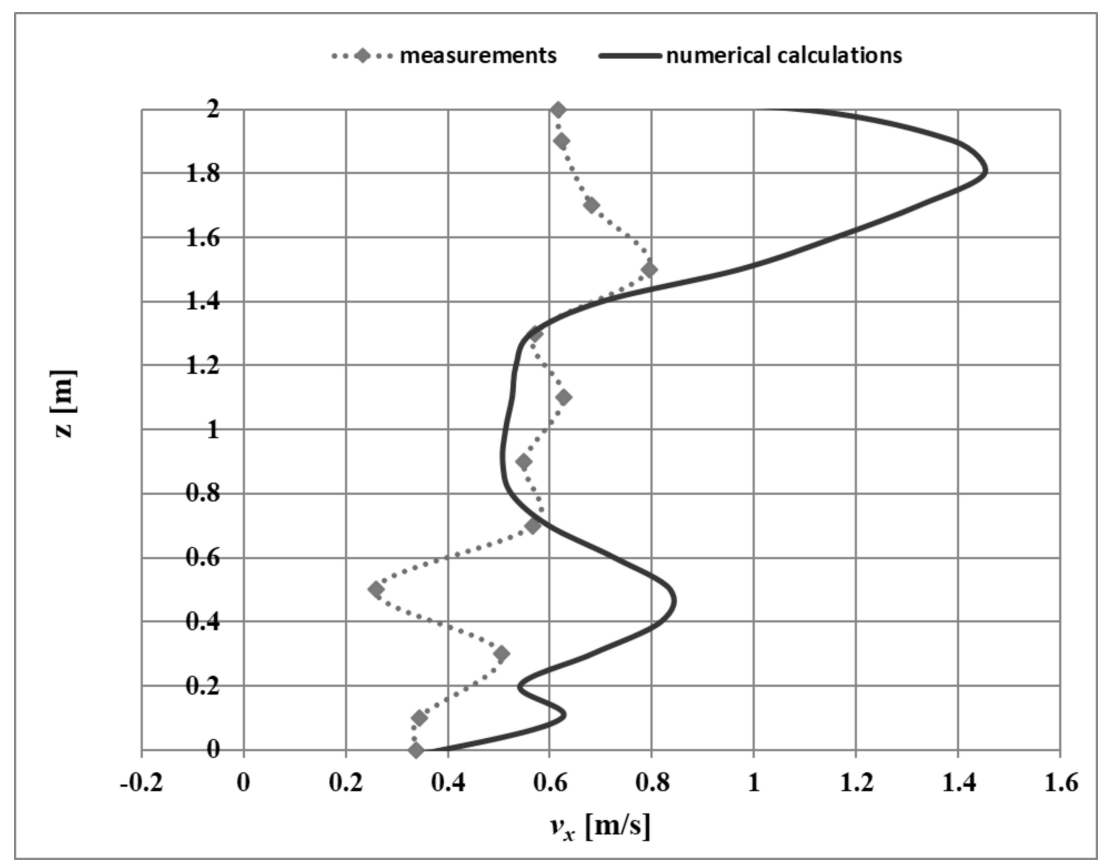

Fig. 16. Velocity distribution in the centre of section 5

\section{Results of Numerical Computations for Alternative II}

Numerical computations for Alternative II were carried out for a period of $400 \mathrm{sec}-$ onds, after which the flow stabilised.

The velocity computation results for section 2 are presented in Figure 17. Negative values of the velocity $v_{x}$ are due to the condition that flow in this section occurs in a direction reverse to the direction Ox in the global system of coordinates. Flow concentration in section 2 occurs in the slot between the baffle elements on the right side of the visible element. The highest velocities of up to $1.8 \mathrm{~ms}^{-1}$ occur in the middle depth, just by the tall, protruding element. In the remaining part of the slot, velocities range from 1 to $1.5 \mathrm{~ms}^{-1}$. In the lower right corner of the section, velocities drop below $0.3 \mathrm{~ms}^{-1}$ because of the submerged baffle element at the wall. On the left side of the visible element, the velocities do not exceed $0.3 \mathrm{~ms}^{-1}$, and by the wall and bottom a reverse current is observed with a velocity of up to $0.4 \mathrm{~ms}^{-1}$. Velocities near the surface are higher, reaching $1 \mathrm{~ms}^{-1}$. This is caused by the shape of the baffle elements, which narrow towards the top, creating a gap between them. The diagram clearly shows that the water table is higher on the left side, because water accumulates there, upstream of the tall baffle elements.

The distribution of velocities in section 3 is shown in Figure 18. The main stream, with velocities reaching up to $1.6 \mathrm{~ms}^{-1}$, flows in the middle part of the section, and stretches diagonally from the upper left corner to the lower right corner. In the lower 
Numerical Modelling of Fish Passage with Turning Pools

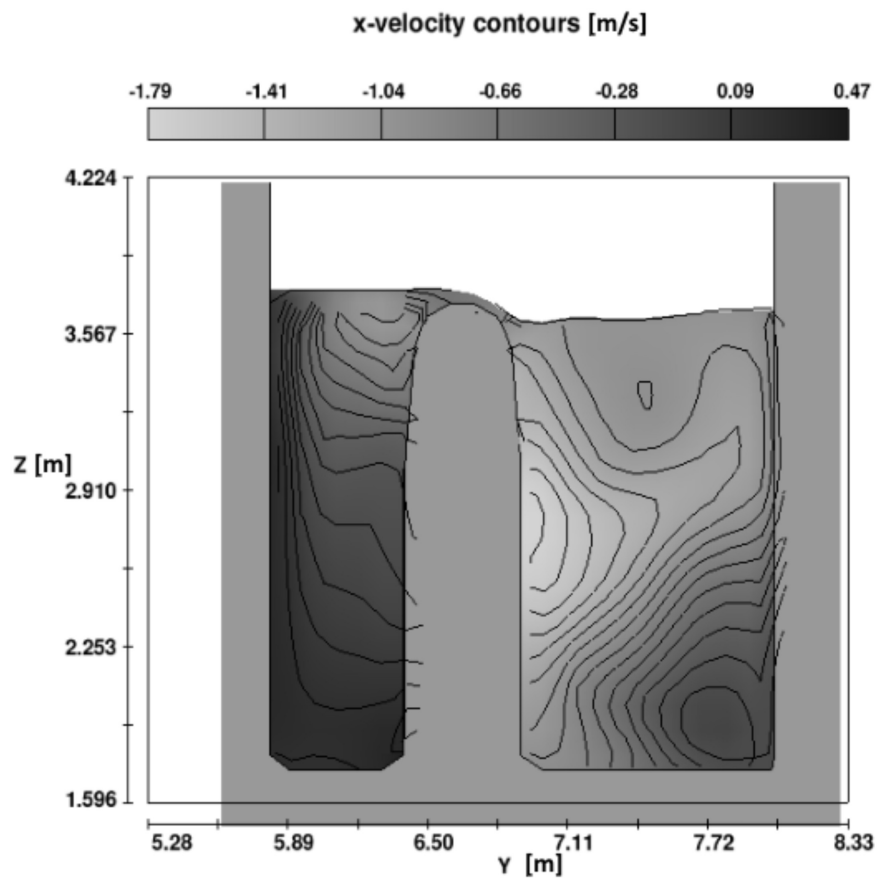

Fig. 17. Computed velocity distribution in section 2 for Alternative II

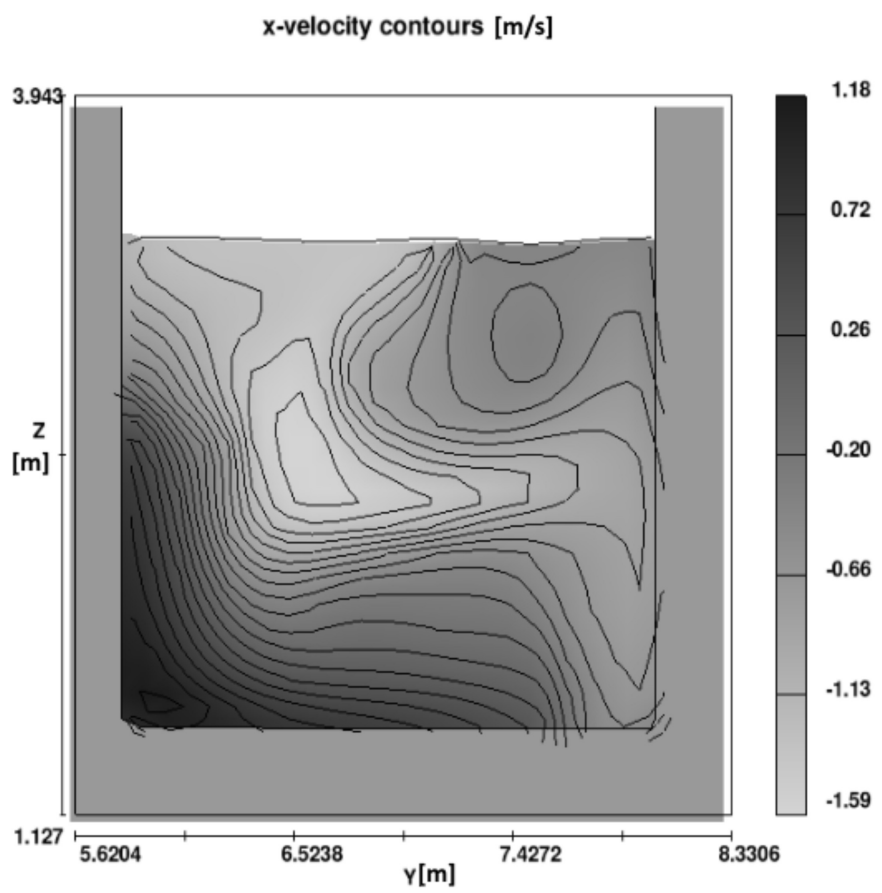

Fig. 18. Computed velocity distribution in section 3 for Alternative II 
left corner, a strong reverse stream occurs, with velocities above $1.1 \mathrm{~ms}^{-1}$, whereas at the bottom and at the left wall the reverse stream is weaker. An area of lower velocities, below $0.5 \mathrm{~ms}^{-1}$, is visible in the upper right corner.

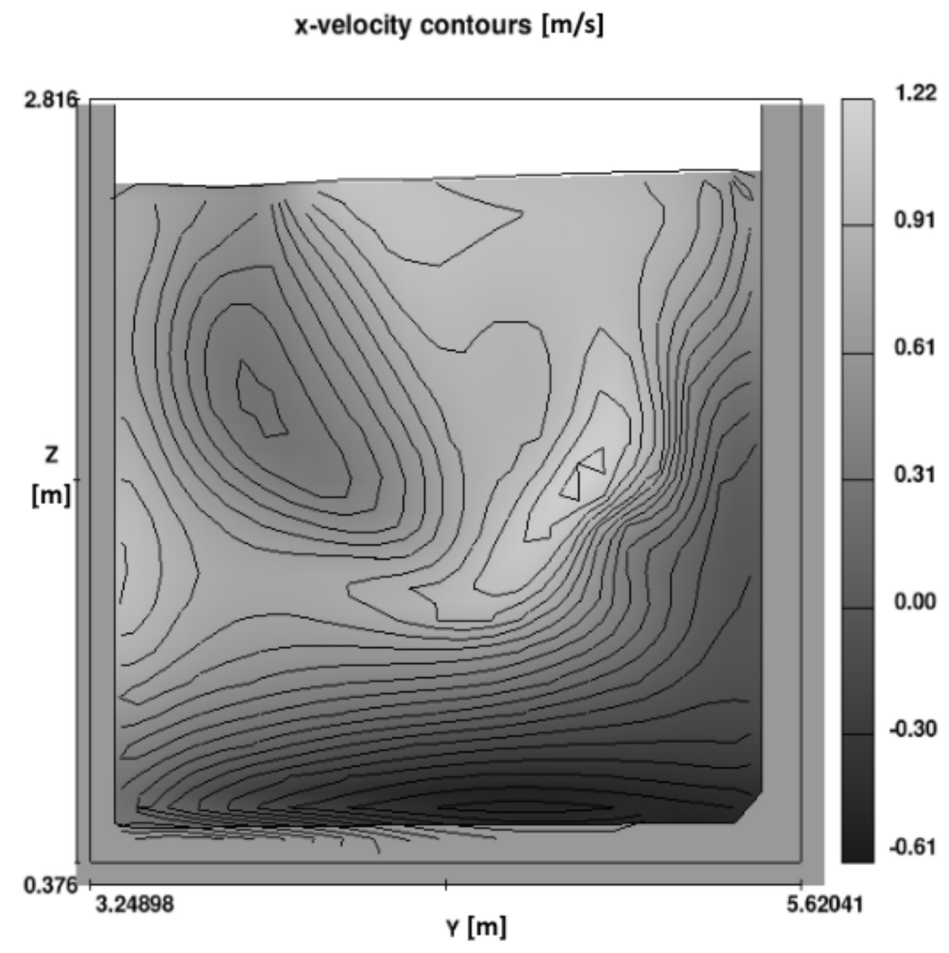

Fig. 19. Computed velocity distribution in section 5 for Alternative II

The distribution of velocities in section 5 is shown in Figure 19. The main stream flows through the right side of the section, but flow velocity differences in the upper part of the entire section are minor. The maximum velocity is $1.2 \mathrm{~ms}^{-1}$, the average is $0.9 \mathrm{~ms}^{-1}$, and at the left wall the velocities locally drop to $0.3 \mathrm{~ms}^{-1}$. At the bottom, however, there is a reverse stream, with maximum velocities of $0.6 \mathrm{~ms}^{-1}$ at the right side of the section.

Figure 20 shows the computed velocity vectors in 3 views at different depths in the fishway exit area. View 1 shows the distribution of velocity vectors just above the bottom, at an elevation of $0.65 \mathrm{~m}$. View 2 shows the distribution of velocity vectors in the middle depth zone, at an elevation of $1.45 \mathrm{~m}$. View 3 shows the distribution of velocity vectors at the surface, at an elevation of $2.45 \mathrm{~m}$. The locations of the views are shown in Figure 21.

In Figure 20a, which shows the velocity vector distribution at the bottom, the stream of water flowing out of the slot is quite quickly diffused in the pool. A vertical vortex forms after the slot, which is due to a mild reverse stream at the wall by the 

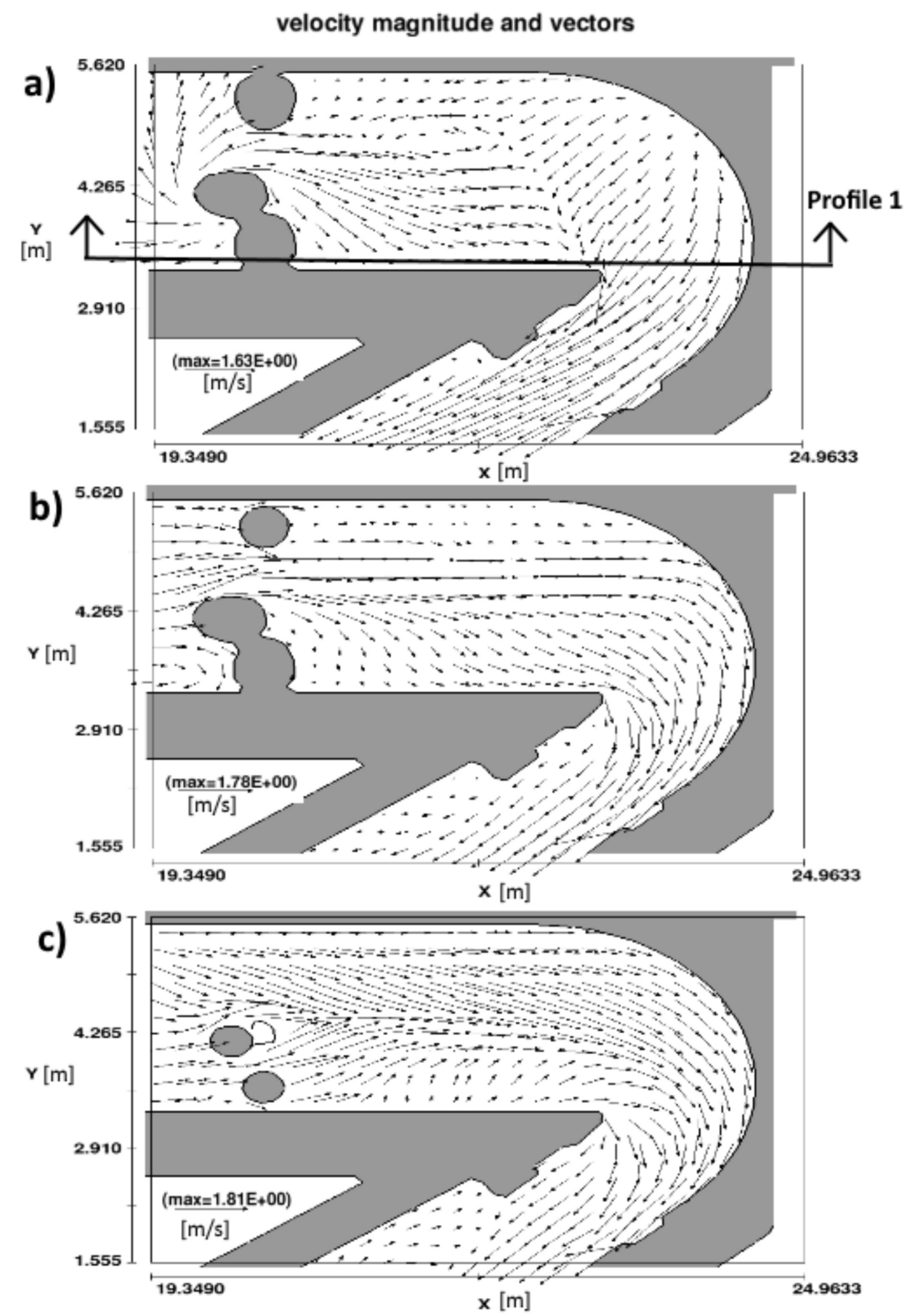

Fig. 20. Computed velocity vector distribution in the entry pool for Alternative II: a) view 1 for $z=0.65, \mathrm{~b}$ ) view 2 for $z=1.45, \mathrm{c}$ ) view 3 for $z=2.45$

concave arc. Velocity vectors in the arc zone are perpendicular to the wall, with the direction of the vectors opposite to the main current. This proves the existence of a horizontal whirl at the bottom of the culvert entry. As the cross-section narrows, the velocities rise, and the vector direction is perpendicular to the pool exit cross-section. The maximum velocity at the bottom is $1.6 \mathrm{~ms}^{-1}$. 
In Figure 20b, which shows the velocity vector distribution at the mid-depth, the main stream, after leaving the slot, is parallel to the axis, until reaching the wall. There is no clear deflection, but the flow is redirected along the arc curve. Therefore, no whirl currents were observed at this depth. The water stream directed smoothly by the pool arc accelerates as it approaches the pool exit, where velocities reach a maximum of $1.8 \mathrm{~ms}^{-1}$.

In Figure 20c, which shows the velocity vector distribution at the water surface, the main stream flows along the wall, on the concave arc side. Smaller streams can also be observed between the tall baffle elements. After passing the baffle barrier, the flow concentrates in the mid part of the culvert. In the arc zone, the velocity vectors are parallel to the arc wall, which means that water passes smoothly by the concave arc. The pool exit cross-section is characterised by higher velocities on the arc side. Maximum velocities reach $1.8 \mathrm{~ms}^{-1}$.

Figure 21 shows velocity vectors in section 1 located in the exit pool, as shown in Figure 20a. In most of the pool, an upward flow predominates, with velocities of about $0.8 \mathrm{~ms}^{-1}$, whereas in the vicinity of the arc wall the dominant direction is reverse, but velocities are lower. This results in a horizontal vortex at the bottom. Its velocities are below $0.5 \mathrm{~ms}^{-1}$, and its diameter can be estimated at $0.5 \mathrm{~m}$. The diagram shows that a fish swimming into the fishway has to pass through the zone between the arc wall and the dashed line, indicating the approximate range of the wall at the convex arc. There it encounters the horizontal whirl, which occupies half of the section at the culvert bottom, or fairly quiet conditions in the upper part of the entry.

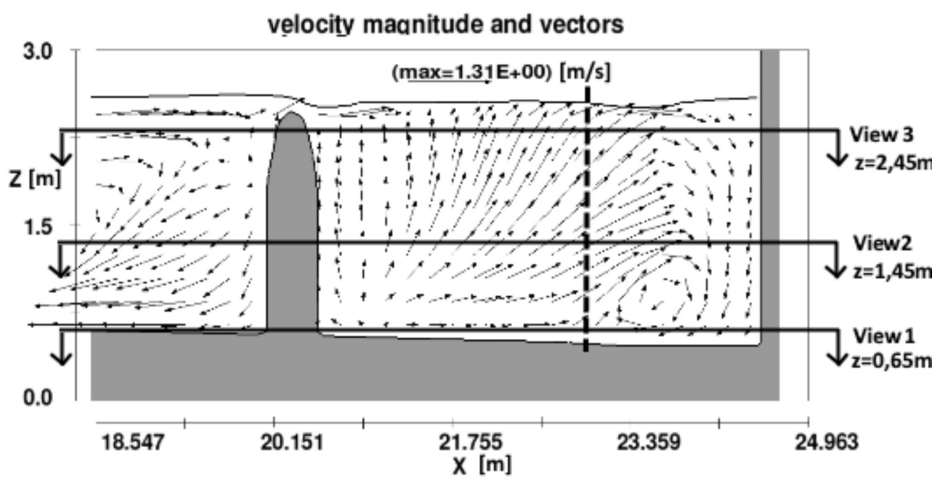

Fig. 21. Computed velocity vector distribution in profile 1 of the entry pool for Alternative II

\section{Comparison of Computations for Alternatives I and II and Conclusion}

The computations carried out for the two baffle setting alternatives indicate large differences in flow conditions. Velocity distributions in section 2 (Fig. 9 and 17) are entirely different due to the arrangement of the baffles. Maximum velocities in both 


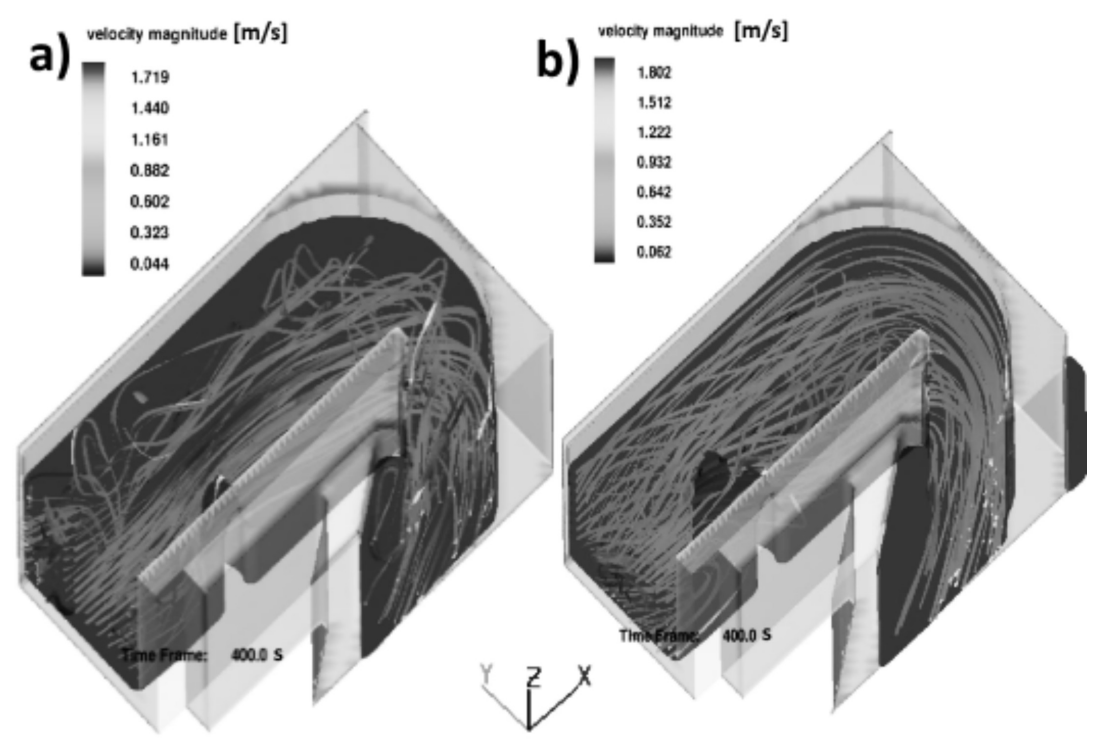

Fig. 22. 3D diagram of water particle trajectories in the exit pool: a) Alternative I, b) Alternative II

alternatives are similar and occur in the immediate vicinity of the baffle. Alternative I, however, shows high velocity gradients, which are not found in Alternative II, where velocity distribution is more uniform. Section 3 (Fig. 10 and 18) is also characterised by a more uniform velocity distribution in Alternative II. Moreover, the maximum velocities are higher in Alternative I, which makes Alternative II more favourable to fish. Section 5 (Fig. 11 and 19) in Alternative I shows flow concentration at the left wall, while in Alternative II the flow concentrates at the right wall. In this section, as well, the maximum velocities for Alternative II are lower, and the velocity distribution is more uniform.

The comparison of velocity vectors in views (Fig. 12 and 20) and in the exit cross-section (Fig. 13 and 21) reveals that the most important difference is the number of whirls forming in the exit pool. In this respect, the more desirable is Alternative II, since there are significantly fewer whirls. Moreover, only one horizontal whirl occurs there, and it is half the size of the whirl in Alternative I, which gives fish a better chance to traverse the exit cross-section. Velocity vector distribution suggests that the flow in Alternative II is more uniform and milder, with maximum velocities lower by about $10 \%$.

An analysis of water particle trajectories was carried out to present more accurately the characteristics of flow in the exit pool. The results of the analysis for both alternatives for a period of 400 seconds are shown in a 3D diagram of water particle trajectories in the exit pool (Fig. 22). Alternative I is characterised by high flow concentration and considerable irregularities. There is also a clearly visible vortex 
just below the water surface. Velocities in Alternative II are lower, and water particle trajectories indicate a smoother flow. The above comparison leads to the obvious conclusion that Alternative II is more favourable for fish migration, especially in an uphill direction.

This study involved site measurements and presentation of water velocity results, as well as numerical computations for a fishway with turning pools having two alternative baffle geometries. The results of computations for Alternative I are consistent with the site survey measurements, which validates the adopted numerical model and the LES method. The 3D numerical model made it possible to reproduce the horizontal vortex effect observed during the site survey in the exit pool of the fishway. The analysis of numerical computation results for the two alternatives confirmed that Alternative II offers significantly better flow conditions, especially in the turning pool. The results show that in order to ensure the correct design of geometrically complex fishways, it is necessary to perform computations using a 3D numerical model with an accurate turbulence model. The LES method is the right choice in this case. It should be pointed out, however, that every numerical model must be verified by measurements in a physical model.

\section{References}

Alvarez-Vazquez L. J., Martınez A., Vazquez-Mendez M. E., Vilar M. A. (2008) An optimal shape problem related to the realistic design of river fishways, Ecological Engineering, 32, 293-300.

Baek K. O., Kim Y. D. (2014) A case study for optimal position of fishway at low-head obstructions in tributaries of Han River in Korea, Ecological Engineering, 64, 222-230.

Barton A. F., Keller R. J., Katopodis C. (2009) Verification of a numerical model for the prediction of low slope vertical slot fishway hydraulics, Australian Journal of Water Resources, 13, 53-60.

Bombač M., Novak G., Rodič P., Četina M. (2014) Numerical and physical model study of a vertical slot fishway Journal of Hydrology and Hydromechanics, 62, 150-159.

Cea L., Pena L., Puertas J., Vazquez-Cendon M., Pena E., (2007) Application of several depth-averaged turbulence models to simulate flow in vertical slot fishways, Journal of Hydraulic Engineering, 133(2), 160-172.

Clay C. H. (1995) Design of Fishways and other Fish Facilities, 2nd edition, CRC Press, Inc. Boca Raton, Florida, USA.

Delavan S. K., Sood S., Pérez-Fuentetaja A., Hannes A. R. (2017) Anthropogenic turbulence and velocity barriers for upstream swimming fish: A field study on emerald shiners (Notropis atherinoides) in the Upper Niagara River, Ecological Engineering, 101, 91-106.

FAO/DVWK (2002), Fish passes - design, dimensions and monitoring, Food and Agriculture Organization of the United Nations, Rome.

Feurich R., Boubée J., Olsen N. R. B. (2012) Improvement of fish passage in culverts using CFD, Ecological Engineering, 47, 1-8.

Gatski T. B., Hussaini M. Y., Lumley J. L. (1998) Simulation and Modeling of Turbulent Flows, Oxford University Press, Inc. New York, USA.

Goettel M. T., Atkinson J. F., Bennett S. J. (2015) Behavior of western blacknose dace in a turbulence modified flow field, Ecological Engineering, 74, 230-240.

Guiny E., Ervine D. A., Armstrong J. D. (2005) Hydraulic and Biological Aspects of Fish Passes for Atlantic Salmon, Journal of Hydraulic Engineering, 131, 542-553. 
Herrera-Granados O. (2018) Turbulence Flow Modeling of One-Sharp-Groyne Field, [in:] Kalinowska M., Mrokowska M., Rowiński P. (eds), Free Surface Flows and Transport Processes, GeoPlanet: Earth and Planetary Sciences. Springer, Cham, 207-218.

Khodier M. A., Tullis B. P. (2013) Fish Passage Behavior for Severe Hydraulic Conditions in Baffled Culverts, Journal of Hydraulic Engineering, 140 (3), 322-327.

Katopodis C., Williams J. G. (2012) The development of fish passage research in a historical context, Ecological Engineering, 48, 8-18.

Kirk M. A., Caudill C. C., Tonina D., Symy J. C. (2016) Effects of water velocity, turbulence and obstacle length on the swimming capabilities of adult Pacific lamprey, Fisheries Management and Ecology, 23, 356-366.

Lee H., Lin C.-L., Weber L. J. (2008) Application of a Nonhydrostatic Model to Flow in a Free Surface Fish Passage Facility, Journal of Hydraulic Engineering, 134, 993-999.

Liao J. C. (2007) A review of fish swimming mechanics and behaviour in altered flows, Philosophical Transactions of the Royal Society B: Biological Sciences, 362, 1973-1993.

Lindberg D. E., Leonardsson K., Andersson A. G., Lundström T. S., Lundqvist H. (2013) Methods for locating the proper position of a planned fishway entrance near a hydropower tailrace, Limnologica, 43, 339-347.

Lupandin A. I. (2005) Effect of Flow Turbulence on Swimming Speed of Fish, Biology Bulletin, 32, 461-466.

Mao X., Fu J-J., Tuo Y-C., An R-D., Li J. (2012) Influence of structure on hydraulic characteristics of T shape fishway, Journal of Hydrodynamics, 24, 684-691.

Marriner B. A., Baki A. B. M., Zhu D. Z., Thiem J. D., Cooke S. J., Katopodis C. (2014) Field and numerical assessment of turning pool hydraulics in a vertical slot fishway, Ecological Engineering, 63, 88-101.

Mortula M. M. (2011) Modeling of a novel fish passage-way using coupled spatially varied flow, Journal of the Franklin Institute, 348, 1627-1637.

Nikora V. I., Aberle J., Biggs B. J. F., Jowett I. G., Sykes J. R. E. (2003) Effects of fish size, time-to-fatigue and turbulence on swimming performance: a case study of Galaxias maculatus, Journal of Fish Biology, 63, 1365-1382.

Odeh M., Noreika J. F., Haro A., Maynard A., Castro-Santos T., Cada G. F. (2002) Evaluation of the effects of turbulence on the behavior of migratory fish, Final Report 2002. Report to Bonneville Power Administration, Contract No. 00000022, Project No. 200005700.

Pavlov D. S., Lupandin A. I., Skorobogatov M. A. (2000) The effects of flow turbulence on the behaviour and distribution of fish, Journal of Ichthyology, 40, Suppl. 2, 232-261.

Richmond M. C., Deng Z., Guensch G. R., Tritico H., Pearson W. H. (2007) Mean flow and turbulence characteristics of a full-scale spiral corrugated culvert with implications for fish passage, Ecological Engineering, 30, 333-340.

Silva A. T., Katopodis C., Santos J. M., Ferreira M. T., Pinheiro A. N. (2012) Cyprinid swimming behaviour in response to turbulent flow, Ecological Engineering, 44, 314-328.

Tritico H. M., Cotel A. J. (2010) The effects of turbulent eddies on the stability and critical swimming speed of creek chub (Semotilus atromaculatus), The Journal of Experimental Biology, 213, 2284-2293.

Yasuda Y., Ohtsu I., Takahashi M. (2004) New portable fishway design for existing trapezoidal weirs, Journal of Environmental Engineering and Science, 3, 391-401.

Wyrębek M. (2013) Baffle fishways as an element of restoration of the continuity of the ecological corridor in strongly changed rivers (in Polish), łInfrastruktura i ekologia terenów wiejskich, 3/I, Polska Akademia Nauk o/Kraków, 61-71. 